\title{
Moral Values and Skills: The Challenges of Space Exploration Practices
}

\section{Olena Shevniuk}

Doctor of Pedagogical Sciences, Professor, National Pedagogical Dragomanov University (Kyiv, Ukraine)

E-mail: shevhelen@gmail.com

https://orcid.org/0000-0002-3247-2374

\section{Olena Matviienko}

Doctor of Pedagogical Sciences, Professor, National Pedagogical Dragomanov University

(Kyiv, Ukraine)

E-mail: Lmatvienko70@gmail.com

https://orcid.org/0000-0002-5746-4864

The present study examines the problem of moral values arising aboard manned spacecrafts. The authors believe that this problem is due to the transition of modern society to the Information Age. Under the conditions of a space flight, when the vital functions of the crew and passengers of a spacecraft are provided and controlled by information and communication technology, the problem of moral values takes on special significance. Information technology, as well as their applications can be divided into three types. These are technologies that record (store), transmit (communicate) and organize information. The authors studied the features of the influence of each type of information and communication technology on moral values and artistic freedom in the microsocial group of a spacecraft. Solving the problem of moral values aboard a manned spacecraft is a sine qua non for artistic freedom during a space flight, the quality of the tasks associated with the colonization of the outer space and the development of material, energy and information resources of the universe.

Keywords: moral values, artistic freedom, spacecraft, space technology, information and communication technology, Information Age

Received: March 3, 2019; accepted: April 11, 2019

Philosophy and Cosmology, Volume 23, 2019: 121-129.

https://doi.org/10.29202/phil-cosm/23/11

(C) Shevniuk, Olena, 2019

(C) Matviienko, Olena, 2019 


\section{Introduction}

Oleg Bazaluk in his book "Space Travels — Traveling Mentality" compiled a chronology of space tourism development relevant for 2012 [Bazaluk, 2012]. Over the past seven years, a lot has changed in space technology. For instance, the article "Explore Space Using Swarms of Tiny Satellites", published in the authoritative journal Nature in October 2018, enables us to draw the following conclusions [Levchenko et al., 2018]:

1. Private business began to invest significantly more in space technology than governments. For example, companies invested about $\$ 262$ billion in 2016, while governments about $\$ 84$ billion. In 2016, the total investment in space technology amounted to $\$ 346$ billion.

2. Space technology has come close to solving the problem of satellites and spacecrafts longevity. As the authors of the article mention: "Longevity is crucial for colonizing the Moon and Mars, where equipment failure might mean life or death" [Levchenko et al., 2018]. If satellites and spacecrafts are to remain functional for a century or more, they need to be able to regenerate - as living organisms do. The technologies are being developed that allow large spacecraft to independently repair damage using small satellites.

3. The issues of human exploration of the Moon and Mars, as well as the extraction and use of the mineral resources of space objects by a man are already considered as a short term perspective. For example, Evgeny Slyuta examines the problems of research and mining of gas deposits on the Moon and points out the feasibility and economic prospects of these projects [Slyuta, 2017].

Given the pace of the development of space technology, as well as their focus on the creation of settlements on the Moon and Mars, on regular communications between the planets, the problem of moral values becomes even more relevant. On board the spacecraft, astronauts do not need to keep a detailed diary of their plans for a day, week, year, possibly decade. Each step is captured by digital technology and systematized by software applications. A personal profile of every astronaut is created, in which millions of fixed records are stored in a digitized form. For example, a detailed list of travel routes and time spent at various places in a spacecraft; records of all conversations and meetings; a list of all web addresses and details of each search on the Internet; a list of all vital physiological functions, such as blood pressure and heart rate; all dietary techniques throughout the day; etc.

Space technology turns the life of an astronaut on a spaceship into an open book in which there is no room for errors. Since, after acquainting with the digitized information of an astronaut's personal profile, like any book after reading it, a special kind of attitude is formed on the part of a spacecraft's commander, crew members, personnel of ground-based flight support services, as well as any person who has gained access to the personal profile. This attitude affects the career of an astronaut, his material support and social status. This is where information and communication technology influences moral values and creates a problem that requires special reflection. This problem is already on the agenda in modern society and makes scientists look for ways to solve it. For instance, in the article "Public Administration of Personal Data Protection in Modern Ukraine", the authors consider the need for the personal data protection as an integral part of informational law and one of the main directions of national information policy. Considering Ukraine as an example, the authors show that, on the one hand, "developed legislative and administrative basis optimizes the scope of information relations, making it tolerant to internal and external threats". However, on the other hand, the lack of legal 
protection of personal data "undermines informational security, provokes conflicts, creates preconditions for manipulation, abuse and harassment" [Gurzhii et al., 2018].

In this article, the authors will consider the impact of various types of information and communication technology on the problem of moral values. Solving the problem of moral values aboard a manned spacecraft is a sine qua non for artistic freedom during a space flight, the quality of the tasks associated with the colonization of space and the development of material, energy and information resources of the universe.

\section{The Two Cultures of the Computer Age}

In the book "Computer Ethics", which contains the most important studies of the ethical issues, there is an article "By the Two Cultures of the Computer Age" by Joseph Weizenbaum, the title of which we have subtitled [Computer Ethics, 2007]. The main essence of the problem of values and technology, morality and machines, is considered by various scientific and philosophical disciplines such as computer and information ethics, medical ethics, journalism, philosophy of information, etc. The need for a comprehensive study of the problem indicates that along with the traditional culture, a new culture is being formed, which is associated with the intensive development of information and communication technology. The development of traditional or classical culture has reached a certain level of understanding. The historical type of cultural practices organization such as high culture, the classical culture industry, global industry of culture are highlighted. The power and politically-technological perspective of the impact of traditional culture on the development of society is considered [Pavlova, 2018]. In its turn, comprehension of the features of information culture influence on a person and society only comes to an understanding of the fundamental values. The "information revolution" has changed social and family life, human relations, education, career, freedom and democracy. Terrell Bynum claims that information and communication technology has changed key human values like life, health, happiness, abilities, knowledge, freedom, security, and opportunities [Bynum, 2018]. Norbert Wiener, when creating this second information and communication culture in the post-war period, aimed at protecting and promoting traditional human values. For example, by working to prevent massive unemployment caused by robotic factories, Wiener tried to preserve security, resources and opportunities for factory workers. Similarly, by arguing against the use of decision-making war-game machines, Wiener tried to diminish threats to security and peace [Bynum, 2018].

However, as a result of the "human-values approach" to computer ethics, a new culture was born in which moral values differ from those of traditional culture, and the term "artistic freedom" implies new meanings and spaces for self-realization. Personal computers, smartphones, Internet technologies, artificial intelligence, robotics, other forms of information and communication technology have created a new form of reality - virtual reality. In virtual reality, the rules of behavior and communication, the ways of self-expression and self-knowledge, cognition and creativity, key skills and abilities have changed. According to "Górniak hypothesis", regional ethical theories like Europe's Benthamite and Kantian systems, as well as the diverse ethical systems embedded in other cultures of the world, all derive from "local" histories and customs and are unlikely to be applicable world-wide. Computer and information ethics has the potential to provide a global ethic suitable for the Information Age [Bynum, 2018]. The Information Age is a transformation of the information and communication culture that Wiener stood at the origins of in "global information ethics" with the global politics, laws, economics, education and values. Designed to preserve traditional values, a new information culture has led to the formation of new values. 
The list of new forms of information and communication technology is constantly growing, but what unites them into a single whole, remains unchanged. This is a kind of computing core with which human users interact mainly through applications and other software operating systems. At the junction of understanding the term "information", the problem of moral values arises.

John Sullins notes that the excellence of information technology is in the direction of manipulating syntax. Mathematicians and engineers prefer to focus on this aspect of information, which is called "syntax." In 1948, Claude Shannon created a mathematical theory of communication in which he described how syntactical information can be turned into a signal that is transmitted in such a way as to mitigate noise or other extraneous signals, which can then be decoded by the desired receiver of the message [Sullins, 2019]. However, so far none of the forms of information and communication technology can understand the semantics or meanings of the information upon which they worked. Information and communication technology cannot distinguish between syntax and semantics. John Searle's "Chinese Room" argument is used to prove this claim. Searle argued that, although machines can be devised to respond to input with the same output as would a mind, machines — unlike minds — lack of understanding of the symbols they process. In the book "Views into the Chinese Room: New Essays on Searle and Artificial Intelligence", leading scientists and philosophers assess, renew, and respond to this challenge to computational cognitive science and artificial intelligence [Views, 2002].

Modern people have to live in an existing conflict of moral values. On the one hand, they are constantly in contact with the two cultures and moral values that have been established in them: traditional and informational. On the other hand, in each of the cultures, the values themselves are constantly transformed. For example, the transition from one technology to another in itself causes a conflict of moral values. Artur Pstuszek revealed the features of these changes on the example of Poland at the turn of the 1980s and 1990s [Pstuszek, 2018].

Lorenzo Magnani argues that existing moral constructs often cannot be applied to new technology, that the technological advances of contemporary society have outpaced our moral understanding of the problems that they create [Magnani, 2007]. Magnani concludes that a person loses the ability to recognize moral values in a rapidly evolving information culture. Therefore, profound ecological changes, human cloning, hybrid people, eroding cyberprivacy and much more are not only manifestations of the Information Age, but also an acknowledgment of the fact that traditional knowledge of moral values is violated. A person loses the ability to think morally, because the slow and conservative process of law and political policy lags far behind the pace of development of information and communication technology. Perhaps this is also due to the paradigm of science change that occurred in the 1960s. Wiktor Możgin believes that it was during this period that a commonly held attitude to university education changed to instrumental. "Pragmatic use of acquired knowledge has become a reference point for many learners. Today the term "university spirit" whose main goal should be to seek the truth seems not to be relevant any more. Nowadays people become more pragmatic and mostly consider the university to be only the next level of his professional career" [Możgin, 2019].

In fact, in modern reality, information and communication technology develops outside the existing legal field, which affirms and defends moral values that dominate the society. Lawrence Lessig is a Harvard Law School Professor who proposed the concept of "free culture", which provides free and open-source software and open spectrum [Lessig, 2007]. Lessig claims that since more than $70 \%$ of young people receive information from illegal sources of information, it is necessary to review existing laws on copyright, access and dissemination of information, 
artistic freedom, etc. In his book "Free Culture: The Nature and Future of Creativity" based on a wealth of factual material, Lessig argues that existing laws limit creativity and the development of culture. A writer, screenwriter, director, artist, any other representative of the creative profession does not have the opportunity to appeal to the authors of other works without their official consent. Any collage made up of different texts or video clips can be punished with a large monetary fine. Copyright law has put artistic freedom within narrow boundaries in which creativity is not able to develop to its full extent. People were actually deprived of their freedom of self-realization and creativity. In the afterword of his book, Lessig called on the society to make a choice: to build a new culture as a free or a feudal one in nature [Lessig, 2007]? Essentially, Lessig called for establishing the moral values and boundaries of the artistic freedom of the Information Age.

\section{The Problem of Moral Values and Artistic Freedom in the Information Society}

Panos Eliopoulos in his article "From the Moral Limits of Personal Interest to the Derogation of Individual Identity: Colonialism and Oppression" examined how latent moral pressure on identity may be a more critical factor than initially considered as regards human action. Eliopoulos concluded that "Moral deterioration into oppression does not merely depend on parameters such as power but also on conceptualizations of power and on the surrender of sovereignty, even for lesser reasons than incapability for action" [Eliopoulos, 2019]. Eliopoulos revealed the fundamental difference between the two approaches, at the origins of which there were two authoritative thinkers: Nietzsche and Mill. He writes that "while for Nietzsche moral liberty is a matter of consciousness and is directly related with personal interest and identity, for Mill morality has to do with norms, rules, and has a canonical influence that produces utility through an altruistic approach" [ Eliopoulos, 2019]. Therefore, starting to consider the problem of moral values and artistic freedom in the information society, we must interpret the origins of this problem. We need to establish whether this problem is born in a person and in the person's natural attitude toward key moral values, or is an ontological orientation towards achieving moral values shaped by society.

The book "Free Culture" by Lessig does not only actualize the problem of moral values and artistic freedom in the information society, but also helps to answer our question. If we design Lessig's ideas for organizing the life of a manned spacecraft, then instead of a general analysis of moral values and artistic freedom in the information society, we restrict ourselves to considering this problem in the microsocial group, which is formed by crew members and passengers of a spacecraft. A spacecraft is an ideal space for considering the above problem, because the life activity on board the spacecraft is provided exclusively by space technology, information and communication technology. We will consider the problem of moral values and artistic freedom using the example of a spacecraft microsocial group.

Lawrence Lessig views himself as a fighter for the freedom of creativity and culture in the information society. This viewpoint brought Lessig a certain fame in the USA, which allowed him to become a candidate for the Democratic Party's nomination for president of the United States in 2016. However, what constitutes freedom and other moral values in a space dominated by space technology, information and communication technology? How far is the very formulation of such a question correct? When Lessig talks about the freedom of creativity and culture in the information society, he unequivocally points to their absence in a traditional culture that is not related to information and communication technology and the virtual world. Thus, Lessig emphasizes the irreducibility of the moral values of traditional 
culture and information one. Are the values and artistic freedom really different in the society on Earth and in the microsocial group of a spacecraft? We will consider this issue in more detail.

Information and communication technologies, as well as their applications, can be divided into three types. These are technologies that record (store), transmit (communicate) and organize information. Consider the features of the influence of these types of information and communication technology on moral values.

The influence of Information Recording on moral values. In the information society, the power of authority implies controlling information. The one who controls information has power. The technologies to produce, record, and store are developing so rapidly that a person has difficulties managing to comprehend their role and significance in their lives. In the Information Age, people are placed in such conditions that they voluntarily record (store) personal information on social networks and on the sites of numerous social institutions: financial institutions, healthcare institutions, universities, state and religious organizations, etc. In most cases, this is confidential information that describes the emotional state of a person, data on his health, financial transactions, mental abilities, hobbies, intentions, etc. Recently, it has become common to accumulate and store all personal information in "the cloud". However, in fact, any recording and storage of information on a digital medium is a voluntary transfer of access to confidential information to third parties. Social institutions, providers that offer "cloud" services, websites that can independently determine which other websites you visited or on which pages of the website you spend the most time, all of these entities gain access to recorded and stored personal information. A person ceases to be the sole bearer of their own secrets and thoughts, as well as independently determine the circle of initiates in their secrets. By transferring the storage of personal data from their own memory to digital media, the person opens access to the secrets to third parties who have a legitimate (or not legitimate) right of access to the stored information. Thus, third parties are vested with a certain power over the user of information and communication technology. The problem of moral values arises as follows. In the history of culture, personal data belonged exclusively to the individual and revealed in their individual self-realization. At its best, a limited and dedicated circle of people had access to confidential information: family members, teachers, and friends. Education, from Plato's theory of education to modern educational theories, specialized in revealing individual characteristics and transforming an individual into a person [Bazaluk et al., 2018]. Thus, moral values were formed by a certain microsocial group, which prepared individual manifestations for socially significant activities, and was the only carrier of confidential information of a person. Accordingly, on the one hand, this microsocial group could fully appreciate the relevance of the moral values of the individual and had a certain responsibility to society for their formation. On the other hand, the person knew the carriers of their personal data by name, and to some extent they determined the circle of initiates in confidential information by themselves. In the information society, and especially on board the spacecraft, access to personal data is essentially global. Formally, according to the instructions, the crew commander, the responsible programmer and several members of the ground-based flight support services have access to personal information. However, in fact, there is no certainty that the personal information recorded by digital media is not accessible to third parties who may use it at their discretion. Under conditions of a space flight, all actions of the crew and passengers are recorded, virtually leaving no room for confidentiality. A man on board the spacecraft is completely open to information and communication technology. There arises a problem of compliance, on the one hand, with the need for transparency of personal information on spacecraft, and on the other hand, with the inability to protect personal information recorded and stored on digital media 
from access by third parties. The question is: is this the format in which Lessig represents the freedom of the information society? Is such freedom consistent with moral value? Essentially, the artistic freedom of astronauts is limited by the fear of lack of confidentiality and the understanding that each of their actions is recorded on digital media.

For instance, is a desire to hide one's malaise not a violation of moral value? On the one hand, a spacecraft doctor is obliged to report the astronaut's malaise to the ship's commander and ground services, as well as possibly inform all crew members. The vital activities of the microsocial spacecraft group and the quality of the fulfillment of the goal depend on this. However, on the other hand, if this ailment is overcome, information about it will still remain on digital media and, possibly, will subsequently be used by third parties. It cannot be avoided that information about this ailment will not affect relations in the family and society, careers, etc. Similar questions arise in relation to other moral values like happiness, abilities, knowledge, etc, which are stored on digital media and at any time can be "taken out of context" and used against the person. In fact, members of the microsocial group of a spacecraft are held hostage by third parties because they lose control of personal data.

Moral Values in Communicating and Accessing Information. Digital technologies forced to rethink privacy approaches based on printing technologies: letters, books, notes, etc. The development of information and communication technology has changed moral values such as privacy, confidentiality, ownership, trust, and the veracity of the information [Bynum, 2018]. The modern generation is grateful for the free help of large Internet companies such as Google or Facebook. However, few people think that in return these companies collect confidential information about each of us, which they use at their discretion. They learned to monetize confidential information. Vito Laterza in her study "Cambridge Analytica, independent research and the national interest" focused on the issue of the influence of private companies which combined data mining, data brokerage, and data analysis with strategic communication during the electoral processes [Laterza, 2018]. The scale of this influence affects all spheres of human activities: from political to spiritual. It gives rise to another problem. It turns out that the struggle for confidentiality of information is not just the struggle for personal control over the information recorded and stored on the media, but restricting the access to confidential information as such. Any provision of confidential information to third parties in return for their services raises the question of the responsibility of these third parties for the storage of personal information. However, as the scandal, associated with Cambridge Analytica, showed, even in the case of evidence of guilt, i.e. non-compliance with information security by a third party, it incurs only financial losses. How can the reputational loss of customers, whose personal information was used without their knowledge, be evaluated?

The problem with complete digital security implies that it rests on the fact that the moral value of security can be in conflict with the moral values of sharing and openness, and it is these later values that guided many of the early builders of information technology [Bynum, 2018]. How far is the moral value of hacking a personal computer comparable with the desire to profit from personal data or to restore social justice? This issue is particularly relevant in the microsocial group of a spacecraft. How far is an authorized access to personal information of astronauts justified? What is the responsibility of a crew member who has decided to authorize access to personal information by a member of the spacecraft microsocial group? How can one manage the information received? How can one evaluate the moral responsibility of such a decision, if it turns out that the acquisition of personal information by an astronaut will be unjustified? After all, the information has lost its confidentiality status and, in fact, privacy and social justice have been violated. 
Moral Values in Organizing and Synthesizing Information. Information and communication technology is not only capable of recording, storing and transmitting personal data. They can systematize information and make decisions based on the results. In the financial sector, it is information technology that makes the final decision on customer value. There are frequent cases when errors in the organization and systematization of information lead to a refusal to issue a loan at a bank, to blocking credit cards, to issuing false information about a client, etc. Decisions made by digital technology are beginning to affect the fate of people, and even the course of historical events. For example, John P. Sullins in his article "RoboWarfare: can robots be more ethical than humans on the battlefield?" compares the ethics of behavior of Telerobotically operated and semiautonomous machines on the battlefield with the ethics of human soldier's behavior on the battlefield. Sullins questions the claims made by robotics researchers that their machines are able to behave more ethically on the battlefield than human soldiers do [Sullins, 2010].

If we consider the ability of information technology to systematize information in the conditions of organizing life activities of a spacecraft, then the problem of moral values will even aggravate. There are questions of responsibility for errors in the systematization of information and communication technology. These errors can lead to the violation of the psychological state of the microsocial group of a spacecraft, to conflict and aggression, to the disruption of a space flight. What is the moral value of the decisions that technology makes? Who should bear moral responsibility for failures in technology and for the consequences of those errors that led to the failures in information and communication technology?

\section{Conclusions}

Our study of the problem of moral values arising aboard manned spacecraft raises more questions rather than provides answers. These questions are indicative of new research on this issue. Consideration of the features of the influence of various types of information and communication technology on moral values and artistic freedom of a spacecraft microsocial group opens up a new space for scientific research. Solving the problem of moral values on board the manned spacecraft is a sine qua non for artistic freedom during a space flight, the quality of the tasks associated with the colonization of the outer space and the development of material, energy and information resources of the universe.

\section{References}

Bazaluk, Oleg. Space Travels - Traveling Mentality. The course of lectures. Kyiv: KNT, 2012. Bazaluk, Oleg, Vasyl Fatkhutdinov, and Denys Svyrydenko. The Potential of Systematization of the Theories of Education for Solving of Contradictions of Ukrainian Higher Education Development. Studia Warmińskie, 55, 2018: 63-79. https://doi.org/10.31648/sw.3062

Bynum, Terrell. Computer and Information Ethics. The Stanford Encyclopedia of Philosophy. Summer 2018 Edition, Edward N. Zalta (ed.), https://plato.stanford.edu/archives/ sum2018/entries/ethics-computer/

Computer Ethics. Edited ByJohn Weckert. Routledge, 2007. https://doi. org/10.4324/9781315259697

Eliopoulos, Panos. From the Moral Limits of Personal Interest to the Derogation of Individual Identity: Colonialism and Oppression. Ukrainian Policymaker, Volume 4, 2019: 4-12. https://doi.org/10.29202/up/4/1 
Gurzhii, Taras, Anna Gurzhii, and Vadym Seliukov. Public Administration of Personal Data Protection in Modern Ukraine. Politické vedy. Vol. 21, No. 2, 2018: 138-158. http:// dx.doi.org/10.24040/politickevedy.2018.21.2.138-158

Laterza, Vito. Cambridge Analytica, independent research and the national interest. Anthropology Today, 34, 2018: 1-2. https://doi.org/10.1111/1467-8322.12430

Lessig, Lawrence. Free Culture: The Nature and Future of Creativity. Penguin Books, 2005.

Levchenko, Igor, Michael Keidar, Jim Cantrell, Yue-Liang Wu, Hitoshi Kuninaka, Kateryna Bazaka \& Shuyan Xu. Explore Space Using Swarms of Tiny Satellites. Nature 562, 2018: 185-187. https://doi.org/10.1038/d41586-018-06957-2

Magnani, Lorenzo. Morality in a Technological World: Knowledge as Duty. Cambridge University Press, 2007.

Możgin, Wiktor. The Condition of a Modern University — Is There a Problem? Future Human Image, Volume 11, 2019: 56-65. https://doi.org/10.29202/fhi/11/6

Pavlova, Olena. Politically-Technological Potential of Cultural Practices in Ukrainian Perspective. Ukrainian Policymaker, Volume 2, 2018: 20-26. https://doi.org/10.29202/ up/2/3

Pstuszek, Artur. The Social Potential of the Polish Art in the Transformation Period. Future Human Image, Volume 9, 2018: 82-91. https://doi.org/10.29202/fhi/9/8

Slyuta, Evgeny. Problems of research and mining of gas deposits on the Moon. Mining of Mineral Deposit. 11(4), 2017: 117-125. https://doi.org/10.15407/mining11.04.117

Sullins, John. RoboWarfare: can robots be more ethical than humans on the battlefield? Ethics and Information Technology. Volume 12, Issue 3, 2010: 263-275. https://doi. org/10.1007/s10676-010-9241-7

Sullins, John. Information Technology and Moral Value. The Stanford Encyclopedia of Philosophy. Summer 2019 Edition, Edward N. Zalta (ed.). https://plato.stanford.edu/ entries/it-moral-values/

Views into the Chinese Room: New Essays on Searle and Artificial Intelligence. Edited by John Preston and Mark Bishop. Oxford University Press, 2002. 